\title{
1. An introduction to Sustainable Entrepreneurship and Entrepreneurial Ecosystems
}

\author{
Eddy Laveren, Robert Blackburn, Cyrine \\ Ben-Hafaïedh, Cristina Díaz-García and \\ Ángela González-Moreno
}

\section{INTRODUCING THE CHAPTERS}

This volume presents nine chapters that demonstrate examples of excellent research in the field of sustainable entrepreneurship and entrepreneurial ecosystems. Sustainable entrepreneurship is widely acknowledged as the answer to the environmental and social challenges that society has faced in recent years (Filser et al., 2019, p. 3). Strategic sustainability decisions are characterized by their importance and the high stakes they entail for several stakeholders. Thus, businesses have a responsibility to participate in setting the agenda for a more sustainable future and it is important to learn more about the factors that drive sustainable entrepreneurship and strategic sustainable decision-making. The entrepreneurial ecosystem (EE) has a significant impact on shaping the entrepreneur's evaluation of prospects that can potentially be realized, since entrepreneurial decisions are inevitably dependent on how individuals judge their entrepreneurial ecosystem.

An entrepreneurial ecosystem can be defined as 'a dynamic community of inter-dependent actors (entrepreneurs, suppliers, buyer, government, etc.) and system-level institutional, informational and socioeconomic contexts' (Audretsch and Belitski, 2016, p. 4). The distinctive features of entrepreneurial ecosystems are that they both enable entrepreneurs to identify market opportunities, and offer local resources, including support and finance, to new, high-growth ventures (Spigel and Harrison, 2018). The success of entrepreneurial ecosystems is based on the interaction of material, social and cultural attributes that provide benefits and resources to entrepreneurs. In regional entrepreneurial ecosystems, universities can be considered as one of the key material attributes. The main social attributes include networks, 
holders of investment capital, mentors, deal-makers and talented workers. The cultural attributes consist of attitudes and histories of entrepreneurship. In a similar vein, Brush (2014) states that the key dimensions of ecosystems are stakeholders, resources, infrastructure and culture. The stakeholders include internal and external stakeholders that have different needs, connections and motivations. Resources include, for example, intellectual knowledge and research capabilities, physical facilities, and monetary and human resources. The infrastructure includes elements related to connectivity, for example technological platforms as well as formal and informal networks. Culture includes norms, values and traditions. The interdependent and multilevel nature of entrepreneurial ecosystems implies the notion of potentially crucial synergistic effects of systems' components, including cross-level interactions (Isenberg, 2011; Prahalad, 2005; Spigel, 2017). Of course, entrepreneurs and their firms are essential ingredients and an outcome of successful entrepreneurship ecosystems (Isenberg, 2011). Volkman et al. (2019, p. 1) highlight that: "while the concept of entrepreneurial ecosystems is now a prominent topic and an important stream in entrepreneurship research, the question of how ecosystems can specifically promote sustainable entrepreneurship and contribute to the Sustainable Development Goals (SDGs) set by the United Nations is a neglected issue'.

This book contributes to filling this gap and aims to serve at the nexus of contextualization of entrepreneurship and sustainability. The chapters in this book are organized in three parts. In Part I, four chapters are presented regarding sustainability or sustainable entrepreneurship. In Part II, two chapters present the entrepreneurial ecosystem orientation as an explanatory factor of entrepreneurial behaviour. In Part III, three chapters give attention to entrepreneurial conditions and behaviour.

\section{PART I: SUSTAINABLE ENTREPRENEURSHIP}

Four chapters (2-5) make up Part I of this book, all focused on sustainable entrepreneurship. Chapter 2 focuses on the concept of the 'circular economy' (CE) as the production model that leads to sustainable results, highlighting both its increasing relevance in entrepreneurship and strategic management journals, and the barriers that European small and medium-sized enterprises (SMEs) encounter within this circular production model. Chapter 3 examines how different combinations of perceived opportunities (including sustainable value) require entrepreneurs to use different decision-logics (effectuation and causation), and how the entrepreneurial mindsets relate to predictive performance regarding competitors (making the opportunity more or less interesting to pursue). Chapter 4 focuses on the drivers of eco-innovations in food and beverage firms. These firms are characterized by their high environmental 
impact, and therefore many firms feel pressured to engage in eco-process innovations. Chapter 5 focuses on understanding how emotion affects strategic sustainability decision-making.

In Chapter 2, Cristina Díaz-García, Ángela González-Moreno and Francisco José Sáez-Martínez analyse the challenges and enablers of businesses to adopt circular economic activities. The authors' starting point is that the linear economy is unsustainable, surpassing the physical limits of the planet, and a shift towards a CE is inevitable. Apart from a more efficient use of resources (materials and waste, energy, water) and products that generate economic gains, the implementation of circular economy business models leads to the creation of entrepreneurial opportunities, the stimulus of innovation and the improvement of environmental protection. The model has been already treated in ecological economics, but it has some important additional contributions to make. These include the importance of materials in the product value chain retaining the highest value possible (for reuse, refurbishment/repair and remanufacturing; and only later for raw material utilization, the main focus in traditional recycling), and that products should be in economic circulation for as long as possible, emphasizing the benefits of the sharing economy.

Despite an increase in academic research on CE in recent years (especially since 2015), and considering that the bulk of knowledge on this issue previously has been developed by policy-makers and practitioners, authors have argued that the literature is unorganized, superficial (remaining largely unexplored) and lacking an economic-business perspective. However, more recently the literature and debates on sustainability have broadened from the domain of environmental management journals to entrepreneurship and strategic management journals. This broadening has also led to a new focus on issues such as sustainability, innovation (for competitiveness) and especially innovation in business models. Within the topic of CE, different sub-topics may be identified. One of these is the challenges and enablers of adopting circular economic activities. In Chapter 2, the authors draw upon the Flash Eurobarometer 441 on European SMEs and the CE. Their literature review and data analysis lead to some implications for policy-makers and academics regarding the importance of SMEs' engagement in the circular economy in this moment of climate emergency.

According to Anna Maija Vuorio and Kaisu Puumalainen in Chapter 3, sustainable entrepreneurship is a particular form of entrepreneurship through which three types of value are created: social, environmental and economic. These types of value creation could also characterize potential entrepreneurial opportunities. However, there is only limited evidence about the attributes of potential entrepreneurial opportunities that include sustainable value creation. Furthermore, although decision-making logics (effectuation versus causation) have gained considerable attention in the entrepreneurship literature, there 
seems to be a lack of studies that focus on decision-making in sustainable entrepreneurship. Additionally, there is limited evidence about entrepreneurial opportunity recognition in sustainable entrepreneurship and the dimensions of a potential entrepreneurial opportunity.

Furthermore, Vuorio and Puumalainen aim to shed light on how decision-making logics and perceptions of entrepreneurial opportunities (novelty, uncertainty, economic value and sustainable value) shape venture performance. Findings in the literature on the impacts of effectuation and causation have been mixed and there is only limited evidence on how these two logics may be utilized in the context of sustainability incentives. Furthermore, Muñoz and Cohen (2018) have put forward a call for alternative methodological approaches to study sustainable entrepreneurship, and thus a machine learning approach is applied in this chapter. Data from 301 Finnish owner-managers in SMEs is analysed using an artificial neural network. First, three alternative mindsets are shown combining the two decision-making logics and dimensions of potential entrepreneurial opportunities. Only one of the mindsets (flexible planner) perceives opportunities, that enable sustainable value creation and are at the same time innovative and uncertain, conditions which are associated with decision-logics of planning and consideration of how much a person can lose combined with flexibility. Second, how these mindsets are connected to different performance outcomes is analysed. The results show that a flexible planner mindset and a networking planner combining causation and elements of effectuation are connected to the perception of better performance compared to competitors' performance. Conversely, an experimenter mindset including only experimentation as an element of effectuation is linked to the perception of worse performance compared to competitors' performance. The empirical results contribute to the literature by using two different decision-making logics and provide evidence to show how these are used, under different conditions together with causation and effectuation, to shape perceptions about performance outcomes. It is a hopeful result that the mindset which detects opportunities enabling sustainable value is also connected with a prediction of better performance than competitors, since this might motivate more potential entrepreneurs to take the leap to sustainable entrepreneurship.

In Chapter 4, María C. Cuerva, Ángela Triguero and Francisco José Sáez-Martínez focus on the food and beverage sector, which is characterized by its high environmental impact and level of emissions because of resource inefficiencies and high rates of food waste, and thus require a transition towards more sustainable practices. Therefore, the sector is pressured to face an eco-innovation challenge including the recovery and treatment of waste, improved production processes, better distribution methods and new packaging solutions. The authors analyse the drivers of eco-process innovations in 
the food and beverage industry taking into account the internal capabilities of the firms and the use of external knowledge sources. The chapter is based on a survey of 279 Spanish food firms. By the specification of probit models, it is shown that the use and the frequency of collaborations with different external partners has a positive effect on the probability of adopting eco-process innovations by food firms. Furthermore, the study reveals that the use of external knowledge from universities, consultants and other external agents is more decisive than collaborations with customers or providers. Finally, a U-shaped relation between age and eco-process innovations is confirmed in this sector. This implies that the adoption of eco-process innovations by food firms is affected both by internal firm characteristics (size, age, financial and technological capabilities) and firms' openness (measured through a diverse collaboration puzzle of external knowledge sources).

The objective of Chapter 5, by Kirsi Snellman and Henri Hakala, is to understand how emotion affects strategic sustainability decision-making. Considering that businesses have a responsibility to participate in setting the agenda for a more sustainable future, it is important to learn more about the factors that drive strategic sustainable decision-making, including the impact of emotions. While emotion may be the enemy of good decisions, other researchers suggest that emotion and reason are complementary in good decisions. Hence, this chapter investigates how emotions affect strategic sustainability decision-making. Drawing on interviews with 23 owner-managers of sustainability 'trailblazing' SMEs, the authors illuminate how emotions complement thinking and rational analysis in sustainability decision-making. This happens through three interrelated elements that link emotion with ethical considerations: sensitizing, sensing and selecting. Sensitizing is associated with an initial awareness of the ethical dilemma; sensing with establishing a global sense of a whole; and selecting with making the ultimate right/good choice. The authors propose a model in which emotion acts as an ethical compass for managers who are subject to multiple forces when making strategic sustainability decisions. The authors' findings indicate that strategic sustainability decisions reflect not only rational reasons and facts, but also associated emotions in addressing ethical dilemmas and an unknown future. The authors suggest that without emotions, there is no readiness to change, nor a willingness to move forward in the strategic decision-making process.

\section{PART II: ENTREPRENEURIAL ECOSYSTEMS}

The two chapters of Part II focus on two specific entrepreneurial ecosystems (EEs): university-based EE (Chapter 6) and Swedish agricultural support EE (Chapter 7). In both cases, institutional members have to be focused to guide 
highly pressured entrepreneurs towards establishing sustainable businesses while operating in highly competitive and complex markets.

Recently, universities have been identified as important contributors in entrepreneurial ecosystems. Universities can provide a large variety of resources to entrepreneurial ecosystems: new technologies that create entrepreneurial opportunities, human capital (teaching and other education activities), knowledge capital (technology and research) and entrepreneurship capital (creation of spin-offs, and entrepreneurial mindset). Additionally, universities may play an important role in creating and connecting entrepreneurs in their networks, thereby enabling entrepreneurs to acquire resources, knowledge and support from the actors of the entrepreneurial ecosystem. University-based entrepreneurship ecosystems can be researched as sub-systems of larger regional or local entrepreneurial ecosystems or as entrepreneurial ecosystems on their own.

In Chapter 6, Katja Lahikainen focuses on investigating a university-based entrepreneurial ecosystem on its own. A university-based entrepreneurial ecosystem (U-BEE) is defined as the strategic and collective actions of various organizational components in order to maximize both the entrepreneurial and the innovative contributions of universities (Hayter, 2016). The chapter aims to discover the underlying factors that influence the emergence of a U-BEE. Current research on U-BEEs focuses largely on organizational-level studies from the university point of view. This study contributes to the existing research by providing new insights to the immature theory development on U-BEEs by giving voice to individuals and comparing the different perspectives of the university and company actors towards the university as a producer of new knowledge, start-ups, entrepreneurs and a skilled workforce.

Lahikainen employs a qualitative case study approach and follows the inductive thematic analysis method. The study is based on 22 thematic in-depth interviews with company and university actors belonging to an emerging U-BEE around a Finnish university campus. The analysis shows that entrepreneurship promotion in the U-BEE is not only about new business creation; rather, the most important role of the university in the ecosystem is to educate entrepreneurs and the high-quality workforce. The emergence of the U-BEE is fostered by scientific excellence, focusing on creating strong dyadic relationships between the university and company actors. However, strong dyadic relationships can also act as a hindering factor, since they might lead to the one-sided development of a specific industrial field. The study suggests that the current theories on U-BEEs should place more weight on entrepreneurial culture and social relations, as well as acknowledge that students are important intermediaries and members in a U-BEE. From the practitioner point of view, the analysis implies that the centralization of entrepreneurship-related 
functions may lead to additional bureaucracy that might hinder the emergence of U-BEEs.

The agricultural entrepreneurial ecosystem operates much in the shadow of what reflects 'real' entrepreneurship and is often neglected in the traditional entrepreneurship literature. Agricultural entrepreneurs globally face the pressure to transform into entrepreneurial models to improve innovativeness and to seek new opportunities and new ways of doing things in the highly competitive landscape. In Chapter 7, Jennie Cederholm Björklund and Jeaneth Johansson acknowledge the situational boundaries embedded in the context of the Swedish agricultural entrepreneurial support ecosystem The key actors in this ecosystem consist of governmental agencies, agricultural advisory organizations, agricultural member organizations and rural societies, among others. At the macro level, the agricultural entrepreneurship support ecosystem may be divided into a governmental system and an advisory system. Parts of the agricultural support ecosystem are studied from different perspectives, but there is no overall picture and understanding of the roles and the challenges faced by advisors in the ecosystem. Agricultural advisors have been subject to much critique, both in practice and in the literature, for not answering agricultural entrepreneurs' needs for support in the ongoing industry transformation. Advisors expect to guide highly pressured agricultural entrepreneurs operating in complex settings towards sustainable businesses in highly competitive markets.

The chapter answers the call to further contextualize agricultural entrepreneurship research by highlighting the specific context of the entrepreneurial agricultural support system in general, and the advisory support system in particular. The researchers collected data by attending 16 meetings involving participation of 34 key actor organizations in the agricultural entrepreneurship support system. These observations were complemented with follow-up semi-structured interviews with key actors and further exploration of the advisors' roles and challenges in the agricultural ecosystem, through the lens of complexity leadership theory (CLT). According to CLT, leadership is considered a phenomenon involving social interactions that causes a shift from emphasizing the human capital of the advisor and the entrepreneurs in the system, to emphasizing social capital. The authors look into advisors' relational leadership and connectedness in the agriculture entrepreneurial support ecosystem and explore the advisors' leadership in coordinating formal and informal work when operating in dynamic agricultural entrepreneurship environments. The authors identify an emergent need for innovation in the leadership of advisory work, and conceptualize enabling mechanisms to accomplish such change. They conclude with the development of a conceptual model that outlines the mechanisms fostering and hindering the support ecosystem's adoption of the new practices and innovation required by the external society. 
The results indicate the need to create an adaptive space for reflection and learning. This space is a relational environment and not necessarily a physical place, that can give innovation the opportunity to flourish through enabling leadership.

\section{PART III: ENTREPRENEURIAL CONDITIONS}

In Part III, three chapters are presented that examine conditions predicting entrepreneurial activity or behaviour amongst postgraduate students (Chapter 8) and employees within organizations (Chapter 9) and how, during the economic recession, social enterprises outperform other enterprises in creating inclusive growth, contributing to solve prevalent societal and environmental challenges (Chapter 10).

In Chapter 8, Clara Cardone-Riportella, Isabel Feito-Ruiz and David Urbano investigate whether the family business background of postgraduate students determines their entrepreneurial intention and behaviour. These students may start their own business, continue as a successor in the next generation of the family business, or work for others outside the family firm. Social cognitive career theory argues that a career choice is a function of the interaction between entrepreneurial self-efficacy, outcome expectations and personal goals. The interaction of these constructs leads to the formation of entrepreneurial intention. Based on social cognitive career theory, evidence from a study of 190 former students of a business administration international postgraduate programme, taught in Spain, indicates that students with a family business background have more entrepreneurial self-efficacy and more entrepreneurial intention than those without this background. However, in terms of entrepreneurial behaviour (starting a new business or being a successor), the direct effect of a family business background is not significant, but the indirect and total effect through entrepreneurial intention is positive and significant. Overall, therefore, these results show that intention precedes behaviour, and that past experience in a family business may influence future behavioural intentions and determine professional career choice.

In Chapter 9, Dagmar Ylva Hattenberg, Olga Belousova and Aard J. Groen explore to what extent organizational conditions stimulate the entrepreneurial mindset (EMS). Employees are at the heart of an organization. The ability and willingness of individuals to rapidly sense, act and mobilize in response to a judgemental decision under uncertainty about a possible opportunity for gain, has the potential to aid organizations in sustaining their competitive advantage in an increasingly competitive environment. The entrepreneurial mindset captures whether one perceives oneself to have the skillset and abilities to act entrepreneurially. 
The scientific knowledge base regarding EMS in an organizational context continues to be fragmented, especially regarding what organizations can do in terms of their environmental conditions to stimulate employees' EMS. EMS is first theorized to be active amongst managers, increasing entrepreneurial initiative and the competitiveness of organizations by influencing their organizational members. The next step is to understand how the EMS of employees can be influenced by organizations. Using a survey method within a Dutch pharmaceutical family firm with offices spread over five countries and three continents, followed by semi-structured interviews with 12 employees, an investigation of EMS in an organizational context is carried out to further understand its interaction with organizational conditions. The results indicate that organizational conditions stimulate the EMS. This implies that organizations can undertake action to influence employees' EMS, for which propositions are formulated.

Chapter 10, by Annu Kotiranta, Saila Tykkyläinen and Kaisu Puumalainen, aims to investigate the growth trajectories of social enterprises in different economic cycles. Social enterprises are seen by politicians and academics as playing an important part in developing more resilient economies and creating inclusive growth. The global economic crisis of 2008 accelerated discussion among European politicians on the potential of social enterprises to contribute to solving prevalent societal and environmental challenges. It has been argued that social enterprises must continue to grow in order to match the scope of these challenges. However, previous research on the topic has not provided compelling evidence on the large-scale effects of social enterprise growth. The results in Chapter 10 are based on robust quantitative methods and matched samples of Finnish SMEs and social enterprises. The authors show that, during the economic recession, social enterprises outperformed other enterprises. Thus, the study provides new evidence on social enterprises' growth performance and contributes to the literature by applying theoretical insights from firm growth research.

\section{OUTLOOK}

Entrepreneurship research regarding sustainable entrepreneurship and ecosystems appears to be evolving and it is intended that this volume adds to this literature, as well as stimulates further research agendas and methodological approaches. Overall, the book demonstrates the vibrancy of research on entrepreneurship and its nexus with the literatures on sustainability and entrepreneurial ecosystems. The chapters present new scientific evidence in the field, together with research-informed policy and practical implications. They also demonstrate the variety of research methods in the field. 


\section{REFERENCES}

Audretsch, D.B. and M. Belitski (2016), 'Entrepreneurial ecosystems in cities: establishing the framework conditions', Journal of Technology Transfer. https://doi.org/ 10.1007/s10961-016-9473-8.

Brush, Candida G. (2014), 'Exploring the concept of an entrepreneurship education ecosystem', in Sherry Hoskinson and Donald F. Kuratko (eds), Innovative Pathways for University Entrepreneurship in the 21st Century, Bingley, UK: Emerald Group Publishing, pp. 25-39.

Filser, M., S. Kraus, N. Roig-Tierno, N. Kailer and U. Fisher (2019), 'Entrepreneurship as catalyst for sustainable development: opening the black box', Sustainability, 11, 4503. doi: 10.3390/su11164503.

Hayter, C. (2016), 'A trajectory of early-stage spinoff success: the role of knowledge intermediaries within an entrepreneurial university ecosystem', Small Business Economics, 47 (3), 633-656.

Isenberg, D.J. (2011), 'The entrepreneurship ecosystem strategy as a new paradigm for economic policy: principles for cultivating entrepreneurship', Babson Entrepreneurship Ecosystem Project, Babson College, MA.

Muñoz, P. and B. Cohen (2018), 'Sustainable entrepreneurship research: taking stock and looking ahead', Business Strategy and the Environment, 27 (3), 300-322.

Prahalad, C.K. (2005), The Fortune at the Bottom of the Pyramid: Eradicating Poverty through Profits, Saddle River, NJ: Wharton School Publishing.

Spigel, B. (2017), 'The relational organization of entrepreneurial ecosystems', Entrepreneurship Theory and Practice, 41 (1), 49-72.

Spigel, B. and R. Harrison (2018), 'Toward a process theory of entrepreneurial ecosystems', Strategic Entrepreneurship Journal, 12 (1), 151-168.

Volkmann, C., K. Fichter, M. Klofsten and D.B. Audretsch (2019), 'Sustainable entrepreneurial ecosystems: an emerging field of research', Small Business Economics. https://doi.org/10.1007/s11187-019-00253-7. 